Federal Reserve Bank of Minneapolis

Research Department

\title{
Coin Sizes and Payments in Commodity Money Systems*
}

\author{
Angela Redish and Warren E. Weber \\ Working Paper 658
}

March 2008

\begin{abstract}
Commodity money standards in medieval and early modern Europe were characterized by recurring complaints of small change shortages and by numerous debasements of the coinage. To confront these facts, we build a random matching monetary model with two indivisible coins with different intrinsic values. The model shows that small change shortages can exist in the sense that changes in the size of the small coin affect ex ante welfare. Further, the optimal ratio of coin sizes is shown to depend upon the trading opportunities in a country and a country's wealth. Thus, coinage debasements can be interpreted as optimal responses to changes in fundamentals. Further, the model shows that replacing full-bodied small coins with tokens is not necessarily welfare-improving.
\end{abstract}

*Redish: University of British Columbia; Weber, Federal Reserve Bank of Minneapolis and University of Minnesota. We thank Aleksander Berentsen, Vincent Bignon, Alberto Trejos, Neil Wallace, Randy Wright, and participants at seminars at the Bank of Canada and the University of Toronto for helpful comments. The views expressed herein are those of the author and not necessarily those of the Federal Reserve Bank of Minneapolis or the Federal Reserve System. 


\section{Introduction}

Modern monetary economies rely on fiat money, largely a 20th century innovation. Prior to that time, commodity monies, in a variety of guises, were used to facilitate exchange. This paper takes the view that there is an important distinction between fiat money and commodity money that has not been given sufficient attention. Specifically, with fiat money - because it is intrinsically useless and inconvertible - there is no necessary link between the physical dimensions (e.g., weight and volume) of money and its value. Under a commodity money regime, however, the need for a variety of denominations created real challenges for monetary authorities, because the coins cannot be too small or too large: attempts to create very small coins were typically short-lived as they faced widespread complaints; large coins were inconveniently heavy. That monetary authorities operating under commodity money standards were not always able to meet these denominational challenges is shown by the recurring complaints about shortages of small changes that disproportionately hurt the poor and the numerous debasements of the coinage.

In this paper, we build a model of a commodity money system in which there is an absence of double coincidence of wants and decentralized exchange. In such an economy, a medium of exchange is essential in the sense that it allows the economy to achieve allocations that could not be achieved without it. Further, the existence of multiple monies with different denominations, which we model as coins of different metals, can improve allocations in the sense of delivering higher ex ante welfare.

Here, we show that introducing and modeling this small complexity to the monetary system helps in understanding the monetary policies of medieval Europe and the complaints of contemporaries about that system. Thus, we agree with Mayhew (2004) who states that "any study of the money supply [in medieval Europe] needs to take account not only of the total face value of the currency, but also of the metals and denominations of which it is composed" (p. 82).

There have been several previous studies that have built explicit models of commodity money systems with multiple coins. Sargent and Velde (2002) build a model with a large coin, which they call a "dollar," and a small coin, which they call a "penny." Denomination issues are introduced by assuming that one of the two goods in their model can only be purchased with pennies. In other words, their model has a "penny-in-advance" constraint in addition to the usual budget constraint. Velde and Weber (2000) build a model with gold and silver coins in which agents get direct utility from the uncoined stocks of these metals that they hold.

These models are subject to several criticisms about their abilities to analyze the problems with commodity money systems. The first is the standard criticism of all cash-in-advance models. It is that the market incompleteness that gives rise to the need for a medium of exchange is simply assumed. It does not arise from fundamentals such as preferences or technologies. The second is that even though coins exist in these models, these coins are perfectly divisible. Therefore, they seem inadequate to address denomination issues, which are essentially issues of indivisibility. Finally, these models are stand-in agent models, so 
that distributional effects of different coin denominational structures cannot be analyzed in them.

There are other studies of commodity money systems that do not use the cash-in-advance framework but rather use a decentralized bilateral matching framework similar to that in this paper. These are the papers by Velde, Weber, and Wright (1999) and Bignon and Dutu (2007). However, these papers cannot fully analyze the issues with commodity money systems because they impose a unit upper bound on money holdings and only permit exchanges of coins for goods. They do not permit exchanges of coins for goods plus coins. Thus, the denomination structure of the coinage, in the sense of the value of coins that can be offered for purchases, is extremely restricted.

In our model we expand the denomination structure of the coinage in several ways. First, our model has two different coins. In this way we capture the historical reality that for most of the last millennium there were bimetallic monetary systems in the West. We generate a demand for large value coins by introducing a cost to carrying coins that is monotonically increasing (we assume linear) in the number of coins that an agent carries.

Second, the model permits exchanges of coins for goods plus coins; that is, change-giving is permitted in our model. This gives our model another attractive feature. In it, the quantity of small coins affects both buyers and sellers. That is, in our model, the terms of trade between buyers and sellers and, in some cases, the ability to trade will depend upon the coin portfolios of both, not just the portfolio of buyers as was the case in, for example, the Sargent and Velde (2002) analysis.

Finally, building on the work of Lee, Wallace, and Zhu (2005), we allow agents to hold multiple numbers of coins. Because agents hold different portfolios in the equilibria of our model, this allows us to have a distribution of rich and poor agents, which is important in the analysis for reasons we discuss below.

It is important to note that throughout the analysis, we maintain the indivisibility of coins, which we regard as a major contributor to the problems with commodity money systems.

The paper proceeds as follows. In section 2, we discuss some stylized facts about commodity money regimes that we want our model to confront. We will draw heavily upon the experience of England for these facts. In section 3, we present our model. In section 4, we present the implications of the model and relate them to the stylized facts. The final section concludes.

\section{Commodity Money Systems}

There are several observations and complaints about commodity money systems with multiple coins that recur throughout the literature on medieval monetary experience. We use our model to confront several of these. Our discussion will focus primarily on the experience of medieval and early modern England. ${ }^{1}$

We note, however, that the model abstracts from two key features of medieval monetary systems. We take the stock of monetary metal as exogenously fixed, and we do not incor-

\footnotetext{
${ }^{1}$ The primary difference between English coinage history and that of the rest of Europe in this period is the lack of a "billon" coinage in England. See below.
} 
porate a unit of account role for money. While primarily driven by a need for tractability, the fixed stocks of metal assumption in part reflects that the choice of denominations was not driven by market forces, but was either a choice of the mint (which typically opted to make fewer larger coins, since they were paid by the weight of metal, not the number of coins) or arbitrarily determined by the monetary authority, as, say, a fixed percentage of mint output. The absence of a unit of account is consistent with the historical fact that no unit of account value was stamped on a coin; coins were known by names such as angel and groat. The monetary authorities did give unit of account values to coins (e.g., an angel was valued at 6.67 shillings in 1469), however, the extent to which coins circulated by tale is debated in the literature. Our assumption precludes the analysis of some policies, such as crying up the value of a coin. Those we leave for another paper.

\subsection{Small change shortages}

One of the common complaints encountered in the literature is that of a scarcity of small change that affected both buyers and sellers. These complaints were almost always accompanied by the claim that such shortages disproportionately hurt the poor.

Prior to 1279, the silver penny was the only coin minted in England. According to Britnell (2004), around 1200 this coin "was an inconveniently large unit for retail trade" (p. 24). It was not until 1279 that Edward I authorized the minting of halfpennies and farthings. The result was by 1300 , "the monetary system could suit the needs of small households better than a hundred years before" (Britnell (2004), p. 24). Mayhew (2004) suggests that while per capita real income in England was essentially unchanged (at 43d.) between 1086 and 1300, the real money stock per capita doubled (from 4d. to 8d.).

However, this situation did not last. As Figure 1shows, English mints produced only a small quantity of halfpennies and farthings. ${ }^{2}$ By the latter part of the 14th century, there were complaints about small change shortages. For example, writing about the situation in 1378 or 1379 , Ruding (1840) states that

certain weights for bread, and measures for beer, such as gallon, pottle, and quart, were ordained by statute, and that they the said Commons had no small money to pay for the smaller measures, which was greatly injurious to them. (p. 237)

Ruding (1840) mentions similar small change shortages in 1380, 1393, 1402, and 1421.

That both buyers and sellers were affected by the shortages is reflected in this passage from Ruding (1840) about the situation around 1444 or 1445:

Men travelling [sic] over countries, for part of their expenses of necessity must depart our sovereign lord's coin, that is to wit, a penny in two pieces, or else forego all the same penny, for the payment of a half penny; and also the poor common retailers of victuals, and of other needful things, for default of such coin of half pennies and farthings, oftentimes may not sell their said victuals and

\footnotetext{
${ }^{2}$ Figure 1 stops in 1351 because mint records break down silver coin production by denomination only between 1279 and 1351 .
} 


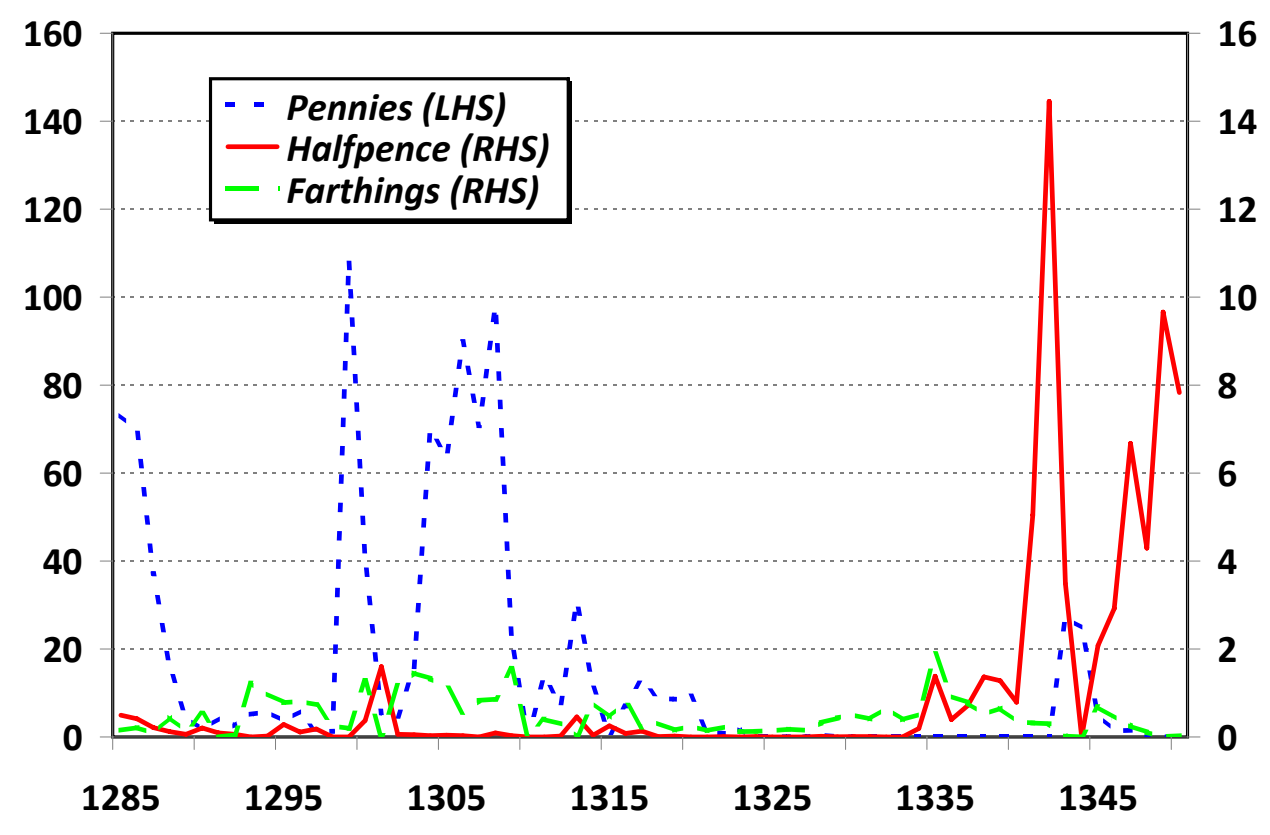

Source: Challis (1992)

Figure 1: London mint: Silver coin output (thousands of pounds)

things, and many of our said sovereign lord's poor liege people, which would buy such victuals and other small things necessary, may not buy them, for default of half pennies and farthings not had on the part of the buyer nor on the part of the seller; which scarcity of half pennies and farthings, has fallen, and daily yet does, because that for their great weight, and the fineness of allay, they be daily tried and molten, and put into other use, unto the increase of winning of them that do so. (p. 275)

The shortages appear to have disappeared after the mid-fifteenth century when the mint output of silver (and gold) increased..$^{3}$

\subsection{Token coins}

By token coins, we mean coins either that are silver but contain less metal than the penny or that are made of a base metal such as copper or lead. Such coins seemed to come into use very frequently during the medieval period. One piece of evidence is that the literature is full of references of the attempts of the English sovereigns to prevent the importation and circulation of foreign token or billon coins. However, it was also the case that at least once some private English tokens were permitted to be used. As Ruding (1840) states, "At an early period of his [Henry VIII's] reign, or about the conclusion of his father's, private tokens

\footnotetext{
${ }^{3}$ Challis (1992) cites John Day's statement that the 1440 s and 1450s were "the low water mark of coinage in late medieval Europe" (p. 190).
} 
were used to supply the want of silver coins" (p. 301). We would like our model to deliver the implication that in an economy without an intrinsically valuable small denomination money, the existence of tokens - by which we mean coins with no intrinsic value — leads to higher welfare.

We will also use our model to examine a claim of Elizabeth I. In justifying an edict to reduce the values of base monies, she proclaimed:

First of all it is known that the honour and reputation of the singular wealth that this realm was wont to have above all other realms, was partly in that it had no current monies but gold and silver, whereas contrary all other countries ... have had, and still have, certain base monies now of late days, by turning of fine monies into base, much decayed and daily grown into infamy and reproach, and therefore is thought necessary to be recovered. (from Ruding (1840) p. 334)

To examine whether Elizabeth's claim is correct, we will use our model to determine the welfare effects of replacing a given supply of token money with the same quantity, in terms of numbers of coins, of intrinsically valuable small denomination money. In other words, we will examine the effects of replacing a given supply of token coins with the equivalent number of intrinsically valuable small denomination coins.

\subsection{Debasements}

According to Sargent and Velde (2002), the medieval monetary "system produced intermittent shortages of small denomination coins, persistent depreciations of small coins relative to large ones, and recurrent debasements of the small coins." (p. 5) Since they provide a very complete and convincing documentation of the debasements of the small coins, there is no need for us to reproduce it here. However, the reader is particularly referred to the graphs on page 16 of their book.

The Sargent and Velde (2002) explanation for debasements is that they were necessary in order to have large denomination coins held. Specifically, in their model some goods can be bought only with small coins. The bindingness of this constraint gives small coins an implicit rate of return advantage over large coins. As a consequence, large coins must appreciate in value relative to small coins in order for them to be held. This causes the price level to increase and eventually leads to the melting of small coins, making the small change shortage worse. Debasements of the small coins reduce their rate of return, preventing the melting of small coins. Thus, rather than debasements appearing to be attempts by sovereigns to increase their revenue, under the Sargent and Velde (2002) interpretation, debasements are welfare-improving actions by the sovereign to keep both small and large coins in circulation.

In our model, both large and small coins circulate and are valued in steady state equilibria with a constant intrinsic value for both coins. Nonetheless, we are intrigued by Sargent and Velde (2002)'s interpretation that debasements could be more than simply revenueraising devices for the sovereign. As a result, we explore the extent to which changes in the ratio of the size of gold and silver coins are optimal responses to changes in an economy's fundamentals. In particular, we will examine whether debasing the small coin is an optimal 
response to an increase in trading opportunities (think: development of organized markets) available to agents in an economy or to changes in a country's wealth.

\section{The Model}

\subsection{Environment}

The model has discrete time and an infinite number of periods. There are $N \geq 3$ nonstorable and perfectly divisible special consumption goods and one general consumption good.

In addition, there are two metals (durable commodities) — silver and gold - in the economy. There are $m_{s}$ ounces of silver and $m_{g}$ ounces of gold in existence. Each ounce of these commodities gives off one unit of the general consumption good at the beginning of each period. ${ }^{4}$ These metals are divisible, but not infinitely so. We will refer to the objects into which these metals are divided as coins. Thus, there can be many silver and many gold coins in the economy, but not infinitely many. In other words, coins are indivisible monies, and the supply of each type of coin must be finite.

The monetary authority in this environment chooses how many ounces of each of these commodities to put into a coin. We let $b_{s}$ be the ounces of silver that it puts in a silver coin and $b_{g}$ be the number of ounces of gold that it puts in a gold coin. Thus, a silver coin yields a dividend of $b_{s}$ units of the general consumption good per coin to the holder at the beginning of a period, and a gold coin yields a dividend of $b_{g}$ units of the general consumption good per coin to the holder at the beginning of a period. The total supplies of the two types of coins are $M_{s}=m_{s} / b_{s}$ and $M_{g}=m_{g} / b_{g}$, respectively.

These gold and silver coins do not have denominations, as was the case with coins throughout most of the time during which commodity monies were used. They are simply amounts of the two metals that have been turned into coins with some type of standardized markings that allow one type of coin to be easily differentiated from a different type of coin. To capture the fact that historically silver coins were less valuable than gold coins, we assume that for technological reasons $b_{s}<b_{g}$, silver coins must be less valuable than gold coins in the sense of yielding a lower dividend per coin..$^{5}$

Letting $s$ and $g$ be an agent's holdings of silver and gold coins, respectively, an agent's portfolio of coin holdings is

$$
y=\{(s, g): s \in \mathbb{N}, g \in \mathbb{N}\} .
$$

Let $\mathbf{Y}=\mathbb{N} \otimes \mathbb{N}$ be set of all possible portfolios.

There is a $[0,1]$ continuum of infinitely lived agents in the model. These agents are of $N$ types, and there is an equal proportion of each type. An agent of type $n$ can produce only special good $n$ and gets utility only from special good $n+1$ and the general good. Let $q_{n}$ denote the quantity of special good $n$. We assume the agent's preferences are

$$
u\left(q_{n+1}\right)-q_{n}+s b_{s}+g b_{g}-\gamma(s+g)
$$

\footnotetext{
${ }^{4}$ Instead of viewing silver and gold as metals, they could be viewed as two different kinds of Lucas trees.

${ }^{5} \mathrm{It}$ is not critical to the analysis that the coins be of different metals. Both coins could be gold or both could be silver. What is important is that the two coins have different intrinsic values (different $\left.b_{j}\right)$.
} 
with $u(0)=0, u^{\prime}>0, u^{\prime \prime}<0$, and $u^{\prime}(0)=\infty$. The disutility of special good production is assumed to be linear without loss of generality. The term $s b_{s}+g b_{g}$ is the utility the agent gets from general goods received by holding coins, and $\gamma$ is the utility cost, also in terms of general goods, that the agent suffers for each coin held coming into a period. ${ }^{6}$

In each period agents are matched randomly. There are two types of matches: no coincidence matches and single coincidence matches. Our assumption on agent types rules out double coincidence matches, and therefore, gives rise to the essentiality of a medium of exchange.

We assume that in any match, the type and coin portfolio of both agents is known. However, past trading histories are private information and agents are anonymous. These assumptions rule out gift-giving equilibria and the use of credit. Thus, trading can only occur through the use of media of exchange, which is the role that the gold and silver coins can play.

\subsection{Consumer choices}

We assume that in a single coincidence pairwise meeting, the potential consumer gets to make a take-it-or-leave-it (TIOLI) offer to the potential seller. This offer will be the triple $\left(q, p_{s}, p_{g}\right)$ where $q \in \Re_{+}$is the quantity of production demanded, $p_{s} \in \mathbb{Z}$ is the quantity of silver coins offered, and $p_{g} \in \mathbb{Z}$ is the quantity of gold coins offered. Offers with $p_{s}<0$ or $p_{g}<0$ can be thought of as the seller being asked to make change.

The set of feasible offers of coins by an agent is

$$
\Gamma^{\prime}(y, \tilde{y})=\left\{\left(p_{s}, p_{g}\right):-\tilde{s} \leq p_{s} \leq s,-\tilde{g} \leq p_{g} \leq g\right\}
$$

where $\sim$ denotes the values for the seller. The restrictions on coin offers are that neither the buyer nor the seller can offer more of a particular coin than he has.

Let $w(s, g): \mathbb{N} \otimes \mathbb{N} \rightarrow \Re_{+}$be the expected value of an agent's beginning of period portfolio of coin holdings. The set of feasible TIOLI offers is a combination of special good output and coins that is a feasible coin offer and satisfies the condition that the seller be no worse off than not trading. Denoting this set by $\tilde{\Gamma}(y, \tilde{y}, w)$,

$$
\begin{aligned}
\tilde{\Gamma}(y, \tilde{y}, w)= & \left\{\sigma: q \in \Re_{+},\left(p_{s}, p_{g}\right) \in \Gamma^{\prime}(y, \tilde{y}),\right. \\
& \left.-q+\beta w\left(\tilde{s}+p_{s}, \tilde{g}+p_{g}\right) \geq \beta w(\tilde{s}, \tilde{g})\right\},
\end{aligned}
$$

where the arguments of $\sigma$ are $\left(q, p_{s}, p_{g}\right)$.

The payoff to the buyer with portfolio $y$ in a trade with a seller with portfolio $\tilde{y}$ is

$$
f(s, g, \tilde{s}, \tilde{g}, w)=\max _{\left(q, p_{s}, p_{g}\right) \in \tilde{\Gamma}(y, \tilde{y}, w)}\left[u(q)+\beta w\left(s-p_{s}, g-p_{g}\right)\right] .
$$

Define the set of optimal offers $\Gamma$ to be the set of optimizers of $f$.

The payoff to the seller in a trade is $\beta w(\tilde{s}, \tilde{g})$. The seller is no better or worse off because the buyer's offer extracts all of the surplus in the trade from the seller.

\footnotetext{
${ }^{6}$ At this point we could have combined $b_{s}, b_{g}$, and $\gamma$ into two net terms. However, it will be convenient later to have separate terms for benefits and costs. In addition, we could have assumed that coins have different costs of being held, but to do so at this point would only complicate the analysis without fundamentally changing the results.
} 


\subsection{Equilibrium}

We will consider only steady state equilibria in this section. There are three components needed. The value functions (Bellman equations), the asset transition equations, and the market clearing conditions. We proceed to describe each in turn.

\section{Value functions}

The steady state value functions are:

$$
\begin{aligned}
w(s, g)= & \frac{1}{N} \sum_{\tilde{s}, \tilde{g}} \pi(\tilde{s}, \tilde{g}) f(s, g, \tilde{s}, \tilde{g}, w)+\frac{N-1}{N} \beta w(s, g) \\
& +g b_{g}+s b_{s}-\gamma(s+g),
\end{aligned}
$$

where $\pi(\tilde{s}, \tilde{g})$ is the fraction of agents holding $\tilde{s}$ and $\tilde{g}$. The first term on the right-hand side is the expected payoff from being a buyer in a single coincidence meeting, which occurs with probability $\frac{1}{N}$. The second term is the expected payoff either from being the seller in a single coincidence meeting or from being in a no coincidence meeting. The final terms are the net utility from holding silver and gold coins.

\section{Asset transitions}

Define $\lambda\left(k, k^{\prime} ; y, \tilde{y}, w\right)$ to be the probability that a buyer with portfolio $y$ in a meeting with a seller with portfolio $\tilde{y}$ leaves the meeting with $k$ silver coins and $k^{\prime}$ gold coins. That is,

$$
\lambda\left(k, k^{\prime} ; y, \tilde{y}, w\right)= \begin{cases}1 & \text { if } k=s-p_{s}(y, \tilde{y}, w) \text { and } k^{\prime}=g-p_{g}(y, \tilde{y}, w) \\ 0 & \text { otherwise }\end{cases}
$$

Then the asset transitions are

$$
\begin{aligned}
\pi_{t+1}\left(k, k^{\prime}\right) & =\frac{1}{N}\left\{\sum_{s, \tilde{s}, g, \tilde{g}} \pi_{t}(s, g) \pi_{t}(\tilde{s}, \tilde{g})\left[\lambda\left(k, k^{\prime} ; \cdot\right)+\lambda\left(s+\tilde{s}-k, g+\tilde{g}-k^{\prime} ; \cdot\right)\right]\right\} \\
& +\frac{N-2}{N} \pi_{t}\left(k, k^{\prime}\right) .
\end{aligned}
$$

The first term on the righthand side is the fraction of single coincidence meetings in which the buyer leaves with $k$ silver coins and $k^{\prime}$ gold coins. The second term is the fraction of such meetings in which the seller leaves $k$ silver coins and $k^{\prime}$ gold coins. The final term is the probability that a meeting is a no coincidence meeting, in which case no coins change hands.

Of course, the asset transition equations must also satisfy

$$
\sum_{s, g} \pi(s, g)=1
$$




\section{Market clearing}

The market clearing conditions are that the stocks of gold and silver coins must be held. That is,

$$
\begin{aligned}
& \sum_{s, g} s \pi(s, g)=M_{s} \\
& \sum_{s, g} g \pi(s, g)=M_{g} .
\end{aligned}
$$

Definition 1 A steady state equilibrium is a $(w, \pi, \Gamma)$ that satisfies the value functions, the asset transition equations, and market clearing.

\section{Results}

We are unable to prove the existence of steady state equilibria or to obtain analytic results for our model. Therefore, we rely instead on computed equilibria for numerical examples to obtain our results. Specifically, for these examples we assume $u(q)=\sqrt{ }(q), \beta=0.9, N=$ $3, m_{g}=0.05$, and $m_{s}=0.03$. For most of our examples we will assume a gold coin size of $b_{g}=0.05$, which implies a per capita supply of gold coins $M_{g}=1$. Because we are interested in small change, we will consider various values for $b_{s}$. Note that because we assume the quantity of silver is fixed, changing the size of the silver coin also changes the number of coins in existence. Further, even though the theoretical model assumes no upper bound on coin holdings, we impose upper bounds $S=40$ on silver coin holdings and $G=2$ on gold coin holdings. ${ }^{7}$ Throughout the analysis our welfare criterion is ex ante welfare, computed as

$$
\bar{w}=\sum_{s, g} \pi(s, g) w(s, g) .
$$

\subsection{Small change shortages}

We first examine the question of whether introducing small (silver) coins to an economy with only large (gold) coins improves welfare. Although we will use the terms gold and silver, one could think of this as the experiment of adding halfpennies (or farthings) to the penny coinage in England. We also examine whether there is an optimal (in terms of ex ante welfare) ratio between the sizes of the coins. Finally we examine how the poor are affected by the introduction of small coins, and how their welfare changes as the size of small coins changes.

Our model's results concerning whether the introduction of small coins improves welfare and whether there is an optimal ratio between large and small coins is given in Figure 2. There we plot as a function of the size of a silver coin the ex ante welfare of the agents in

\footnotetext{
${ }^{7}$ For several cases we also computed equilibria assuming $S=30$ and $G=3$. These equilibria did not differ much from the equilibria reported in the text.
} 
an economy with both gold and silver coins over that if only gold coins (or only pennies in the case of England) were in existence. ${ }^{8}$

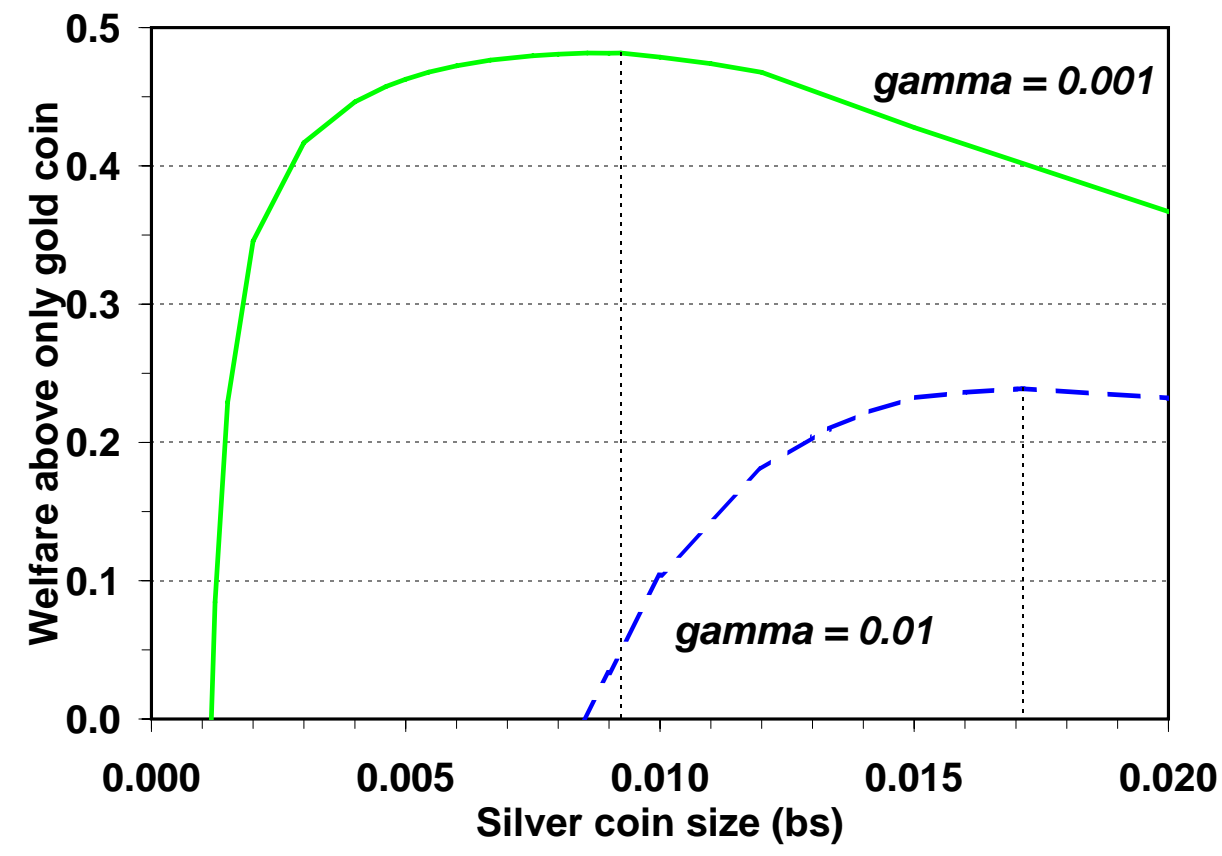

Figure 2: Welfare from the addition of small coins of various sizes for different $\gamma$

The figure illustrates our interpretation of small change shortages under a commodity money system in two senses. One, the addition of silver coins to gold coins (or halfpennies or farthings to pennies in the case of England) improves ex ante welfare. ${ }^{9}$ Both lines in the figure lie above zero for some sizes of small coins. Two, if silver coins exist, decreasing the size of the silver coin can improve welfare. Intuitively, this occurs because the smaller the silver coin, the more precisely the buyer can adjust the TIOLI offer made to the seller.

However, the figure also shows that this is only the case when the silver coins are not too small. After some point, ex ante welfare falls as the size of the silver coin is decreased. (The dotted lines mark the silver coin size that yields maximum ex ante welfare for each of the $\gamma$ 's.) Further, the lines (solid when $\gamma=0.001$ and dashed when $\gamma=0.01$ ) intersect the $\mathrm{x}$-axis for $b_{s}>0$. When the silver coins are very small, so many of them are in existence that the cost of holding them exceeds their intrinsic value plus their value in trade. In such a case, agents would prefer to throw them away rather than hold them. Not surprisingly, the minimum size for a small coin such that agents are willing to hold it increases as the cost of holding coins increases, as shown by the fact that the dashed line intersects the $\mathrm{x}$-axis to the right of the solid one. ${ }^{10}$

\footnotetext{
${ }^{8}$ For the gold coins only case, we assume that agents still get per capita dividends of $m_{s}$, so that the change in welfare is due strictly to the addition of silver coins, not to the addition of silver per se.

${ }^{9}$ We also checked whether adding gold coins to an economy with only silver coins would improve welfare and found that it did.

${ }^{10}$ For $\gamma=0.01$, the dashed line intersects the $\mathrm{x}$-axis for $b_{s}<0.01$. Thus, in this case it is welfare improving
} 
Because ex ante welfare is not always decreasing in coin size, there is an optimal size ratio between the two coins. The figure shows that this ratio decreases as the cost of holding a coin increases.

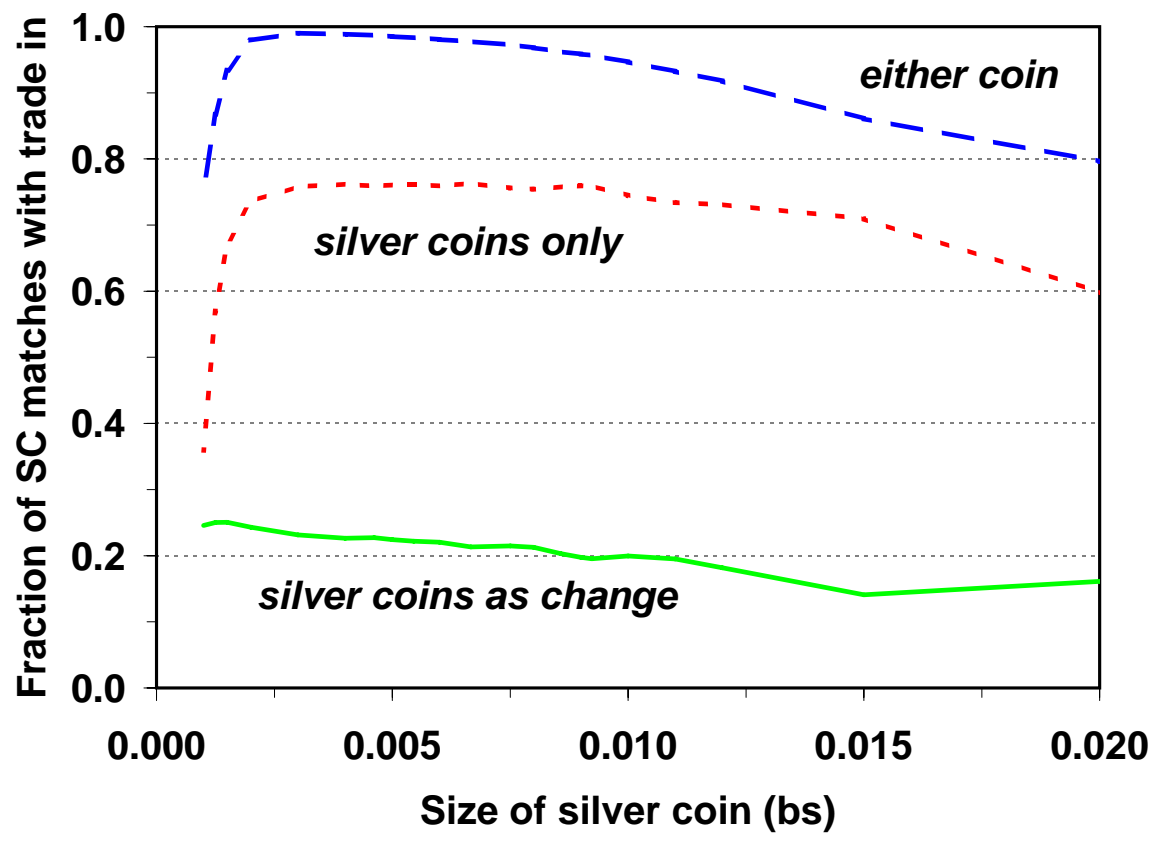

Figure 3: Fractions of matches by type of trade and size of silver coin, $\gamma=0.001$

We also examine how the welfare gains from the ability of agents to give a smaller coin (that is, to give up a smaller amount of intrinsic value) in transactions arise. This is done in Figure 3 where we show the fraction of single coincidence matches in which trade actually occurs, in which the payment is silver coins only, and in which the payment is gold coins with silver coins given as change. ${ }^{11}$ To put the results in the figure in context, if there were only gold coins, trade would occur in only 0.44 of the matches.

The figure shows that trade occurs in more matches as silver coins get smaller. In fact, until the point at which agents no longer want to hold silver coins because they have become too costly, trade occurs in almost all matches. The figure also shows that the fraction of trades in which silver is involved increases as silver coins get smaller. The figure also shows

to have silver coins in addition to gold coins even if the cost of holding a silver coin is greater than its intrinsic value. This is due to the fact that silver coins are useful in trade. However, this is not true when $\gamma=0.001$. There the intrinsic value of the silver coin must be greater than the cost of holding it in order for the addition of silver coins to be welfare improving.

${ }^{11}$ To compute these fractions we calculated

$$
\sum_{s, \tilde{g}, \tilde{g}} \pi(s, g) \pi(\tilde{s}, \tilde{g}) I(s, g \tilde{s}, \tilde{g}),
$$

where $I(s, g, \tilde{s}, \tilde{g})$ is an indicator function thats takes on the value of 1 if trade or trade of particular type occurs in a match between an agent holding $(s, g)$ and an agent holding $(\tilde{s}, \tilde{g})$. 
that the fraction of trades in which silver coins are given as change increases as silver coins become relatively small, but this is not the case when they are relatively large. ${ }^{12}$

Lastly, in this section we examine the claim that the shortage of small denomination coins falls hardest on the poor. We do this in two ways. First, we look at how the welfare of an agent with a given wealth in terms of silver coins changes as the size of the silver coin changes. That is, we calculate how $w(s, g \mid \bar{w})$, where $\bar{w}=s b_{s}$ is some value of the agent's silver coin wealth, varies as the size of the silver coin varies. Because we are concerned with poor agents, we consider only agents who hold no gold coins, which is why gold coin holdings do not appear in $\bar{w} \cdot{ }^{13}$ Second, since the pattern of trade affects the distribution of agents' coin holdings, we will examine how this distribution is affected as the size of the silver coin varies.

The effects of changes in small silver coin size on the welfare of agents with small amounts of silver coin wealth are shown in Table 1 . The entries in the table are agents' welfare by metallic content of silver coin holdings. The entries in the second column are for a silver coin size of $b_{s}=0.01$, which from Figure 2 is close to optimal size of the silver coin. The entries in the third column are for a larger silver coin size $b_{s}=0.015$. The entries in the fourth column are for an even larger silver coin size $b_{s}=0.02$. Note that the implied coin holdings for a given metallic content of silver coin holdings differ by column. For example, for a metallic content of 0.06 , an agent is holding 6 coins when $b_{s}=0.01,4$ coins when the metallic content is $b_{s}=0.015$, and 3 coins when the metallic content is $b_{s}=0.02$. This is why there are gaps in the table.

Table 1 shows that small change shortages have a greater effect on the poor. The welfare of agents with small amounts of silver coin wealth $(\leq 0.05)$ increases as the silver coin becomes smaller. After that level of wealth, however, this is no longer always the case, and as an agent's silver coin wealth becomes large enough, the agent would prefer to have larger size silver coins.

Next, we examine how changing the size of the silver coin affects the distribution of wealth. This is shown in Figure 4, which plots the cumulative distribution of agents by their wealth in terms of silver coins (recall that $g=0$ ). The figure shows that the fraction of agents with little such wealth falls sharply as the size of the silver coin is decreased. Specifically, when $b_{s}=0.02$, approximately 14 percent of agents have no wealth at all and approximately 25 percent have wealth in terms of silver coins of 0.02 or less. When $b_{s}=0.015$, the percentages fall to roughly 10 and 22, respectively. And when the size of the small coin

${ }^{12}$ We also examine whether the size of the silver coin affects the quantity of goods traded in a match. To do this, we measure the average $q$ that is exchanged in a match. That is, we compute

$$
\bar{q}=\sum_{s, g \tilde{s}, \tilde{g}} \pi(s, g) \pi(\tilde{s}, \tilde{g}) q(y, \tilde{y})
$$

where $q(y, \tilde{y})$ is the quantity of goods exchanged in a match between an agent with portfolio $y=(s, g)$ and an agent with portfolio $\tilde{y}=(\tilde{s}, \tilde{g})$. We find that the average quantity of goods traded in a match decreases as the supply of silver coins increases. If one wanted to say that the total money supply in this economy was the total number of silver and gold coins, then this result can be interpreted as saying that increasing the money supply (or, to use slightly different language, debasing the coins) is inflationary.

${ }^{13}$ Consistent with Mayhew (2004)'s comment cited in the introduction, we find that for similar values of total coin wealth, $s b_{s}+g b_{g}, w(s, g)$ is different for different $(s, g)$. 


\begin{tabular}{c|rrr}
$\begin{array}{c}\text { Silver } \\
\text { coin wealth }\end{array}$ & \multicolumn{3}{|c}{ Welfare } \\
\hline \hline 0 & $b_{s}=0.01$ & $b_{s}=0.015$ & $b_{s}=0.02$ \\
\hline 0.01 & 0.00 & 0.00 & 0.00 \\
0.02 & 0.35 & & \\
0.03 & 0.63 & & 0.53 \\
0.04 & 0.86 & 0.83 & \\
0.05 & 1.06 & & 0.98 \\
0.06 & 1.23 & & \\
0.07 & 1.39 & 1.43 & 1.37 \\
0.08 & 1.53 & & \\
0.09 & 1.67 & & 1.70 \\
0.1 & 1.80 & 1.89 & \\
& 1.92 & & 2.00
\end{tabular}

Table 1: Welfare by metallic content of agents wealth holdings for various coin sizes

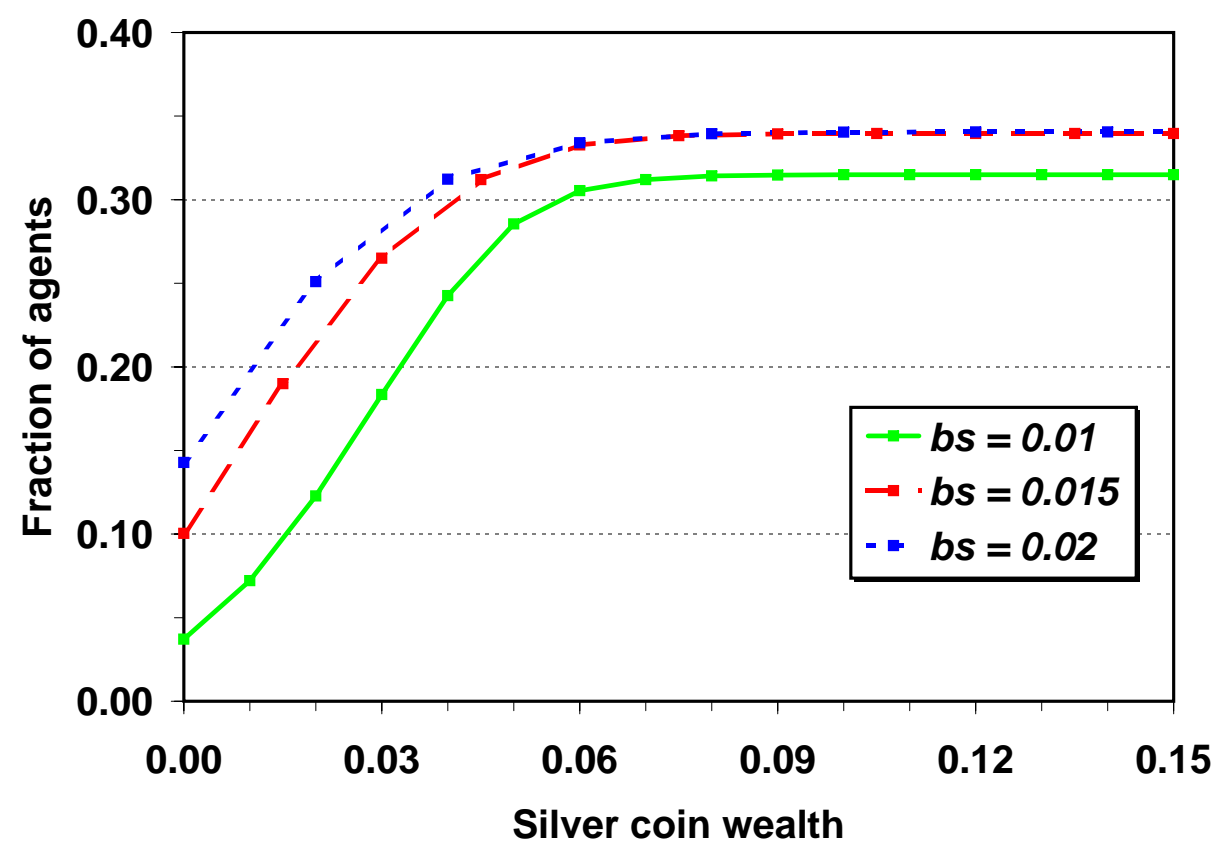

Figure 4: Fractions of agents with $g=0$ and various levels of silver coin wealth for various sizes of silver coins, $\gamma=0.001$ 
falls to $b_{s}=0.01$, the percentages are approximately 4 and 12 , respectively. Note that the fraction of agents with larger amounts of wealth in silver coins is approximately the same over the three coin sizes and is invariant to coin size. This further shows that variations in the size of small coins have the largest effects on the poor.

\subsection{Token coins}

In this section we examine whether ex ante welfare is higher with token coins or with fullbodied coins as claimed in the earlier quote from Elizabeth I. For this, we compute ex ante welfare for various quantities of tokens and silver coins, where we define a token to be a coin with no intrinsic value. To keep the intrinsic wealth the same in the two cases, we assume the same $m_{s}$ in both. That is, in terms of the value function, we assume that $b_{s}=0$ and add $m_{s}$. Further, we assume that silver coins and tokens have the same carrying cost. Our justification is that such coins were "liable to be soon worn, and easily lost" (Ruding (1840), p. 281).

The results are shown in Figure 5. We find that ex ante welfare is higher with token coins than with full-bodied silver coins when the quantity of silver coins or tokens is small. However, the opposite is true when the quantity of silver coins or tokens is large.

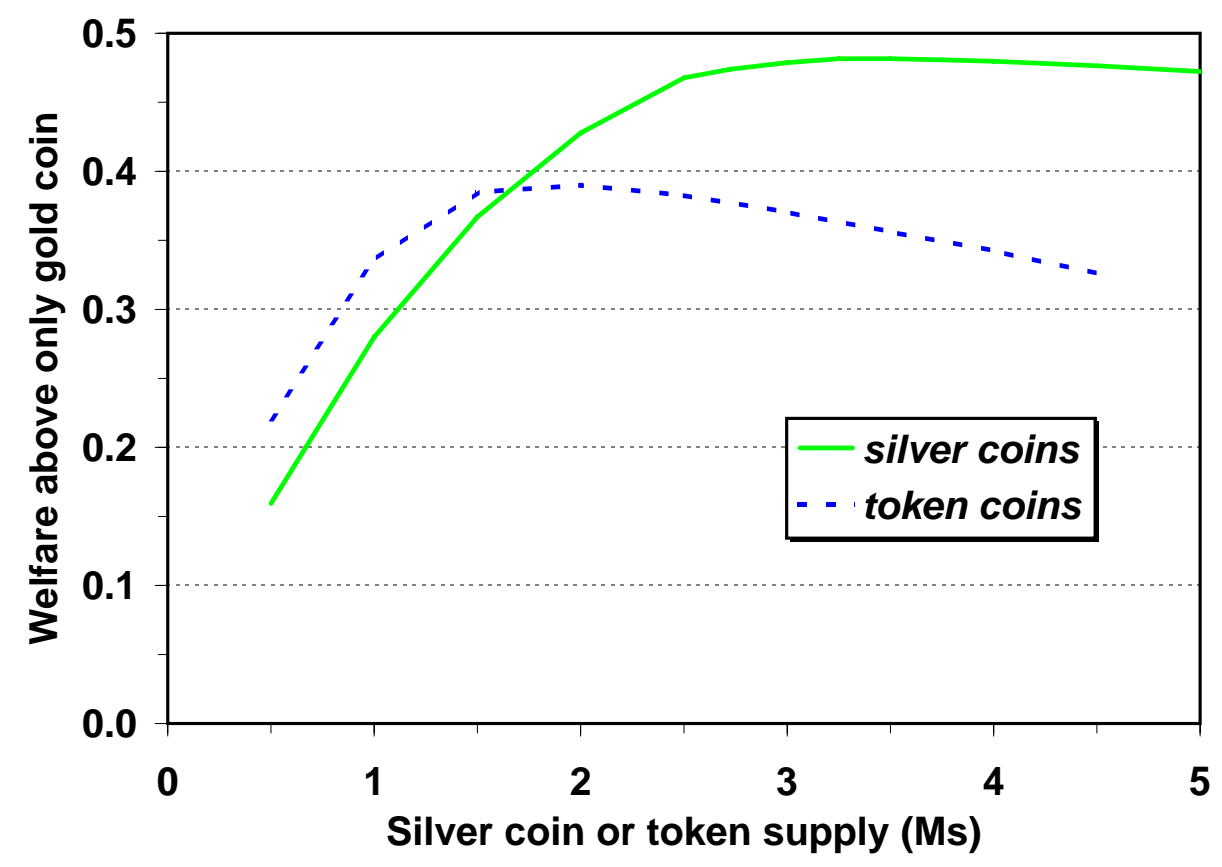

Figure 5: Ex ante welfare for various quantities of silver coins and tokens, $\gamma=0.001$

The intuition for the result is that when the quantity of silver coins is small, silver coins are close to gold coins in value and are only marginally beneficial in facilitating trade. Tokens enable more trades to occur because they fill in a "denomination gap" in the coinage structure. This usefulness in transactions offsets the cost of carrying around the token. 
However, as silver coins become smaller, this denomination gap shrinks and silver coins become preferred because their intrinsic value helps to offset the costs of carrying them.

Stating this slightly differently, silver coins have intrinsic value and value in trade. Tokens have only value in trade. When silver coins are large, their value in trade is small relative to that of tokens. Smaller silver coins have higher value in trade and this, added to their intrinsic value, makes them preferred to tokens.

\subsection{Debasements}

Finally, we examine another possible interpretation of why debasements occurred which, as in Sargent and Velde (2002), does not look at them simply as revenue devices for the sovereign. Instead, we examine whether changes in the ratio of the size of gold and silver coins can be interpreted as optimal responses to changes in an economy's fundamentals. In particular, we examine whether debasing the small coin is an optimal response to an increase in trading opportunities (think: development of organized markets) available to agents in an economy or to changes in a country's wealth.

In the model, the probability of a single coincidence trade decreases with $N$, so decreasing $N$ can be interpreted as an increase in the trading opportunities available to agents in the economy. To examine whether debasements could be an optimal response to an increase in the trading opportunities available in an economy we compute ex ante welfare for various sizes of silver coins, holding the size of the gold coin fixed for $N=3,6,10$. Throughout we assume that $\gamma=0.001$.

The results are shown in Figure 6. When $N=10$, that is, when an agent has a one-in-ten chance of having a single coincidence match in any period, the ex ante welfare maximizing size of the silver coin is $b_{s}=0.015$, which, given that we have assumed a gold coin size of $b_{g}=0.05$, gives an optimal ratio of $3 \frac{1}{3}: 1 .{ }^{14}$ When $N=6$, the figure shows that the optimal size of the silver coin falls to $b_{s}=0.011$, or an optimal ratio of approximately $4 \frac{1}{2}: 1$. And when $N=3$, the optimal coin size is $b_{s}=0.0092$, for an optimal coinage ratio of approximately $5 \frac{1}{2}: 1$. Thus, our model indicates that debasing the silver coins would be an optimal response to an increase in a country's trading opportunities.

Intuitively, the smaller the silver coin, the more finely a potential buyer is able to calibrate an offer of wealth (in the form of coins) for goods to a potential seller. The finer the wealth offer that a buyer can make, the less likely it is that the buyer will have to take a smaller quantity of good from the seller in exchange for a given wealth transfer or have to give up additional wealth to get the desired quantity.

Obviously, buyers would like to have silver coins be infinitely small. However, the benefits of making finer offers have to be traded off against the costs of carrying more coins. When a buyer has a high probability (the $N=3$ case) of being in potential trade matches, the benefits of finer offers is high and small silver coins are preferred. But these benefits fall as trade occurs less often, so larger silver coins are preferred. ${ }^{15}$

\footnotetext{
${ }^{14}$ We have not made any attempt to try to calibrate our model to any actual coin ratios of the period.

${ }^{15} \mathrm{We}$ only discuss buyers because our TIOLI offer assumption means that all surplus is extracted from sellers.
} 


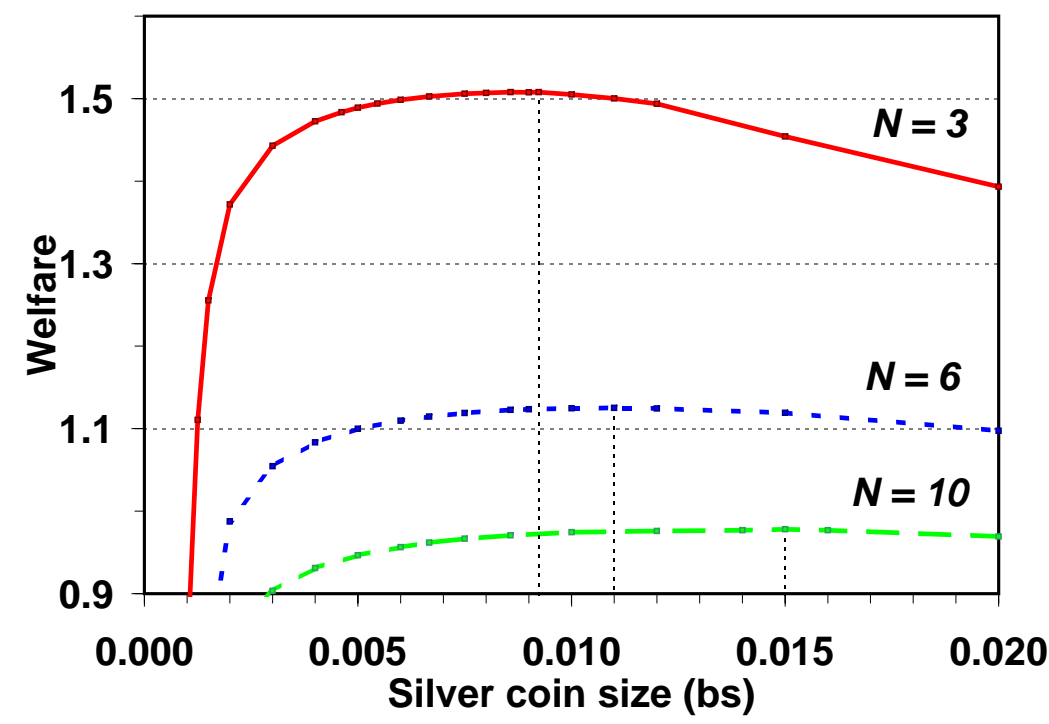

Figure 6: Ex ante welfare as a function of silver coin size for various $N, \gamma=0.001$

Next we examine how the optimal ratio of the size of gold to silver coins changes as the metallic wealth of a country increases. To do this, we compare ex ante welfare for the original case in which $m_{s}=0.03, m_{g}=0.05$ with the case when $m_{s}=0.02, m_{g}=0.033$ and the case when $m_{s}=0.015, m_{g}=0.025$. That is, we compare optimal coin sizes for three countries: the original, one which has two- thirds the metallic wealth of the original, and one which has half the metallic wealth of the original.

The results are shown in Figure 7. The top line is the same ex ante welfare line that was at the top of Figure 6 , the $m_{s}=0.03, m_{g}=0.05$ case. It shows that the optimal size of the silver coin is $b_{s}=0.0092$, as before. The dotted line is for the $m_{s}=0.02, m_{g}=0.033$ case when metallic wealth is two-thirds as large. The optimal coin size in this case is smaller, $b_{s}=0.006$. The dashed line is for the $m_{s}=0.015, m_{g}=0.025$ case when metallic wealth is half as large. The optimal coin size in this case is even smaller, $b_{s}=0.005$. Thus, our model indicates that as a country's wealth increases, as measured by the stock of metals that its agents hold, it should silver coins make its silver coins larger.

Intuitively, as the metallic wealth of a country increases, the distribution of wealth shifts and there are fewer poor agents in the economy. As a result, potential buyers must offer more wealth to potential sellers in order to get them to produce. Hence, small silver coins become less useful in trade because they convey less wealth yet are costly to carry. Hence, the increase in ex ante welfare from larger silver coins falls as metallic wealth increases.

Thus, if one is looking for a fundamentals-based explanation of debasements being optimal, our model suggests it lies in expanding trade opportunities rather than increased wealth. 


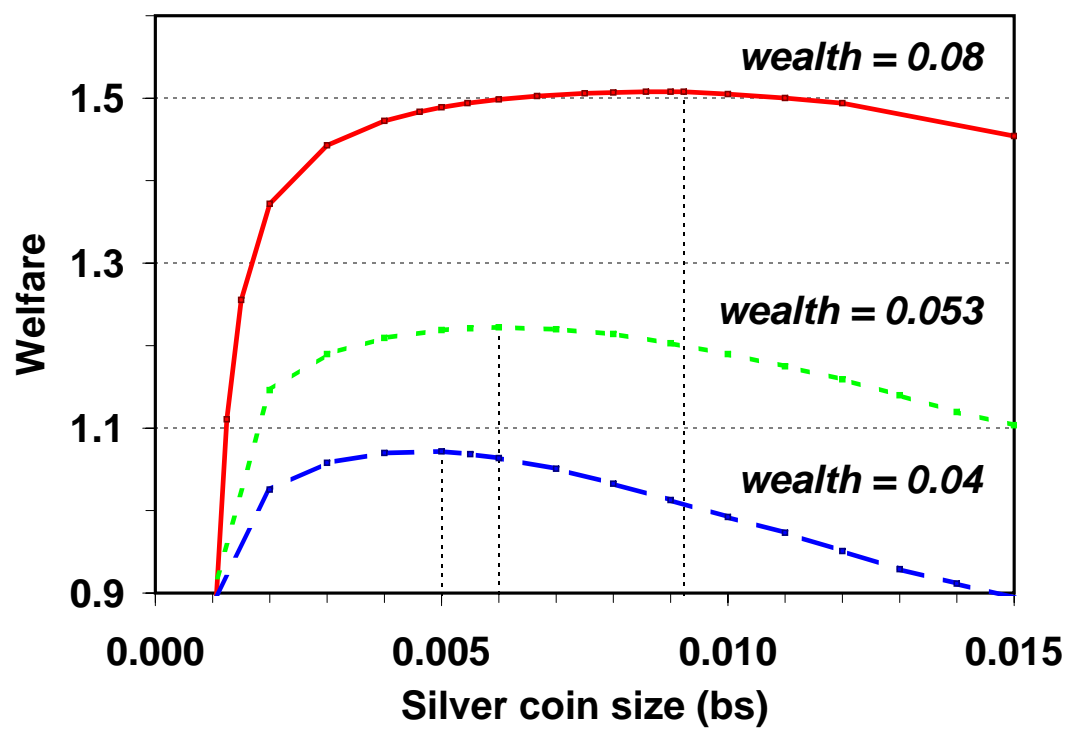

Figure 7: Ex ante welfare as a function of silver coin size for various levels of metallic wealth, $\gamma=0.001$

\section{Conclusion}

During much of the period during which countries operated under commodity money standards there were recurring complaints about shortages of small change that disproportionately hurt the poor and about numerous debasements of the coinage. To confront these facts, we build a random matching monetary model with two indivisible coins with different intrinsic values. We permit exchanges of goods for coins of either or both types as well as exchanges of goods and coins of one type for coins of the other type, we permit agents to hold more than one coin.

The model can confront the facts about how commodity money systems operated. Small change shortages can exist in the sense that changes in the size of the small coin affect ex ante welfare. Further, the optimal ratio of coin sizes is shown to depend upon the trading opportunities in a country and a country's wealth. Thus, coinage debasements can be interpreted as optimal responses to changes in fundamentals. Further, the model shows that replacing full-bodied small coins with tokens is not always welfare-improving.

One limitation of the model is that supplies of coins are assumed to be fixed. That is, minting and melting of coins is not permitted. We hope to address this limitation in future research. 


\section{Bibliography}

Bignon, V., And R. Dutu (2007): "Moneychangers and Commodity Money," Manuscript, University of Paris.

Britnell, R. (2004): "Uses of Money in Medieval England," in Medieval Money Matters, ed. by D. Wood, pp. 16-30. Oxbow Books, Oxford, England.

Challis, C. (1992): A New History of the Royal Mint. Cambridge University Press, Cambridge.

Lee, M., N. Wallace, and T. Zhu (2005): "Modeling Denomination Structures," Econometrica, 73(3), 949-960.

Mayhew, N. J. (2004): "Coinage and Money in England, 1086-c.1500," in Medieval Money Matters, ed. by D. Wood, pp. 72-86. Oxbow Books, Oxford, England.

Ruding, R. (1840): Annals of the Coinage of Great Britain and its Dependencies, vol I. Printed for J. Hearne, London, 3d edn.

Sargent, T. J., And F. R. Velde (2002): The Big Problem of Small Change. Princeton University Press, Princeton, NJ.

Velde, F. R., And W. E. Weber (2000): "A Model of Bimetallism," Journal of Political Economy, 108(6), 1210-1234.

Velde, F. R., W. E. Weber, and R. Wright (1999): “A Model of Commodity Money, with Applications to Gresham's Law and the Debasement Puzzle," Review of Economic Dynamics, 2(1), 291-323. 